\title{
CONCENTRATION OF PRECIPITABLE IODINE IN THE SERUM ${ }^{1}$
}

\author{
By DAVID M. KYDD, EVELYN B. MAN, AND JOHN P. PETERS
}

(From the Department of Internal Medicine, Yale University School of Medicine, New Haven)

(Submitted for publication March 17, 1950; accepted, April 24, 1950)

As an aid in the diagnosis of disturbed function of the thyroid gland in patients with equivocal clinical symptoms, the measurement of precipitable iodine in serum (SPI) can be used only if its range in euthyroid, hypothyroid and hyperthyroid individuals is defined precisely. Winkler (1) presented a chart of serum iodine values in these conditions. However, not only precipitable iodines but also total iodines were included, and the latter, due to inclusion of inorganic iodine, may be erroneously high. Usually this error amounts to from 1.0 to 2.0 gamma per cent, but occasionally gross errors occur after excessive intake of inorganic iodine or contamination (2). The normal range of SPI reported by others has been similar to that reported by Winkler, but the maximal variation has not been clearly defined (3-7). Continued study has also revealed that pituitary or adrenal disease, pregnancy, metabolic disturbances accompanied by disturbed serum proteins, and other conditions to be discussed may, in themselves, be associated with a diminution or increase of the SPI (8-11).

To analyze these abnormalities, re-examination was made of the original values of SPI in physiologically normal individuals and in patients with untreated, unmistakable hypo- and hyperthyroidism (Figure 1). In the present series only values for iodine precipitated with serum protein have been used in normal and hyperthyroid persons. The inclusion of total iodines in the euthyroid and hyperthyroid series might give unduly high values owing to the presence of inorganic iodine. In the hypothyroid group, however, some total iodines have been included, because in a certain number of hypothyroid patients only the total iodine was determined prior to therapy. Recently these patients have never stopped thyroid medication for a sufficiently long period to allow measurement of the inherent SPI. That these values ( $T$

1 Aided by grants from the U. S. Public Health Service and the James Hudson Brown Memorial Fund of the Yale University School of Medicine. in Figure 1) are erroneously high is quite possible, because whatever inorganic iodine happened to be in the serum would be included. However, since the amount of iodine in the serum of hypothyroid patients is less than normal, this error decreases rather than enhances the distinction between the values found in normal and hypothyroid persons.

To establish normal values it has not been considered sufficient that the person was euthyroid. None of the 80 individuals in the normal group had any demonstrable physiological abnormality, nor did any of them have any known close relations with thyroid abnormalities. No patients were included in the normal series whose SPI had been determined in order to exclude hypo- or hyperthyroidism suspected because of a basal metabolic rate above or below the range of +15 to - 15 per cent of normal, bradycardia, tachycardia, vasomotor instability, obesity or other symptoms sometimes associated with thyroid dysfunction.

The patients included in this study do not represent all the hypo- and hyperthyroid patients whose SPI's have been studied in this laboratory. The hyperthyroid group includes those patients who are being treated in this clinic with thiourea or propylthiouracil and, in addition, a sufficient number taken consecutively from the laboratory files to make a total of 200 patients with hyperthyroidism. While this sampling is not complete, no instances of the disease have been omitted from the consecutive series and expansion beyond 200 cases did not seem necessary. The 93 patients with hypothyroidism are those whose clinical course substantiates the diagnosis.

The SPI of hyperthyroid patients was in all cases obtained prior to therapy or at least six months after any possible previous therapy. In most instances the patients had had no treatment for thyrotoxicosis, but 16 per cent of the individuals had recurrent hyperthyroidism and in years past may have had Lugol's solution, subtotal thyroidectomy, or both. 


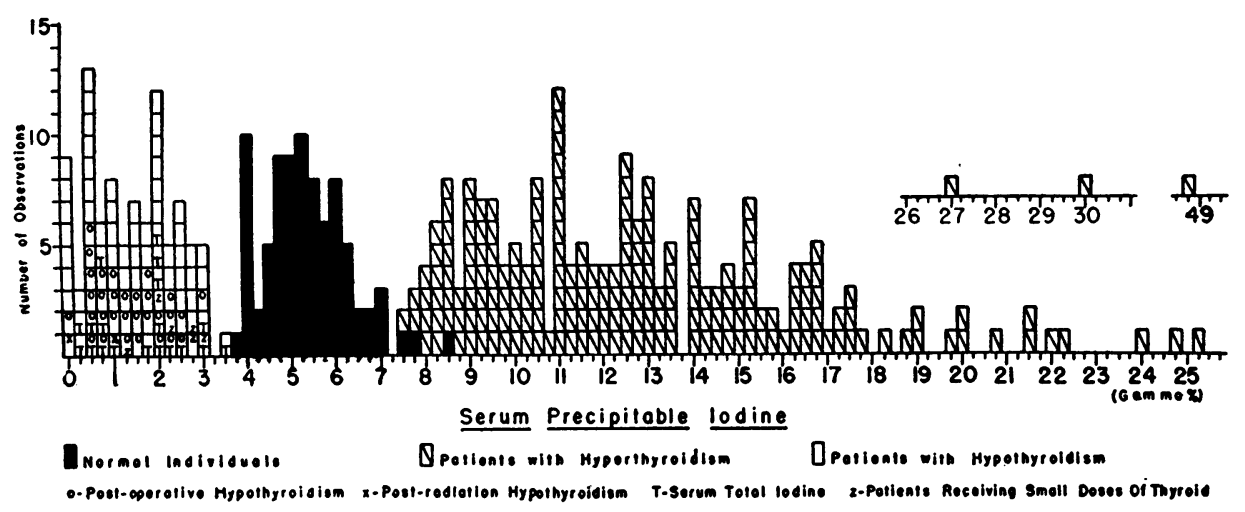

Fig. 1. Serum Precipitable Iodine in Euthyroid, Hypothyroid and Hyperthyroid INDIVIDUALS

Fifty-three of the 93 hypothyroid patients were adults with myxedema which had developed spontaneously, nine were infants or young children of whom six were classified as cretins, and the remaining 31 patients had hypothyroidism subsequent to subtotal thyroidectomy or radiation therapy. Studies that were obtained less than six months after subtotal thyroidectomy have been omitted because Winkler (12) noted a transient hypoiodinemia during the first three or four months following this operation. All patients in this series had sufficient evidences of thyroid deficiency to require continued administration of desiccated thyroid for relief of symptoms. Patients who became hypothyroid while receiving an antithyroid drug have been excluded.

\section{METHOD}

All results are the average of two duplicate determinations which are required to agree within 1 gamma per cent. Prior to July, 1949, the SPI was determined by the method previously described $(13,14)$ which requires $6 \mathrm{ml}$. of serum for a single determination. Since July, 1949 , a micro procedure which requires only $1 \mathrm{ml}$. of serum for a single determination has been substituted. The proteins are precipitated with zinc hydroxide in the digestion flask. After washing, the precipitate is digested with potassium permanganate and sulfuric acid and the digest is distilled into an acid arsenite solution while it is reduced by oxalic and arsenious acids. Iodide in this solution is estimated in Chaney's recording colorimeter $(15)^{2}$ by the rate at which the color of ceric

2 Dr. Albert L. Chaney of Glendale, California, kindly constructed a continuously recording colorimeter for us and provided much advice and many other courtesies. Mr. Joseph Doolittle of Yale has given invaluable aid with electronic equipment. Arrangements have been sulfate fades when it is reduced by arsenite in the presence of iodide. This color reaction has been employed by numerous other observers (15-23). Efforts to employ polarography, spectrophotometry with starch or amylose, or electrometric titrations for the measurement of iodide had not met with success.

\section{Apparatus}

Pyrex precipitation and digestion flasks, illustrated in Figure 2.

Distilling head, with water-cooled condenser, described in detail in the legend to Figure 2.

Antibumps or ebullators, glass rods with open ends, total length $9 \mathrm{~cm}$. (13).

Perforated watch glass (Figure 2).

Pyrex beakers, $100 \mathrm{ml}$., high form with lip.

Centrifuge, with head to take six $250 \mathrm{ml}$. cups (if such a centrifuge is not available, the serum could be precipitated in small tubes and, after centrifuging, the precipitate could be transferred to the digestion flasks).

Continuously recording colorimeter, described by Chaney (15).

Pyrex test tubes, $100 \mathrm{~mm} . \times 12.9 \mathrm{~mm}$. (external diameter).

\section{Reagents}

Double distilled water, from alkalinized distilled water $(13,24)$. The 12-liter all-glass distilling flask may be heated conveniently with Glas-Col mantles. Double distilled water is used throughout the procedure and for the preparation of all reagents.

Somogyi's (25) solutions for precipitation of blood protein, prepared in the manner described for the macro procedure (14).

Sulfuric acid, $27 \mathrm{~N}, 750 \mathrm{ml}$. of concentrated sulfuric acid (Mallinckrodt C. P. analytical reagent, low nitrogen) are poured slowly into $375 \mathrm{ml}$. of water.

Potassium permanganate, recrystallized in the manner described for the macro procedure, except that the crys-

made with National Technical Laboratories to construct this recording colorimeter. 


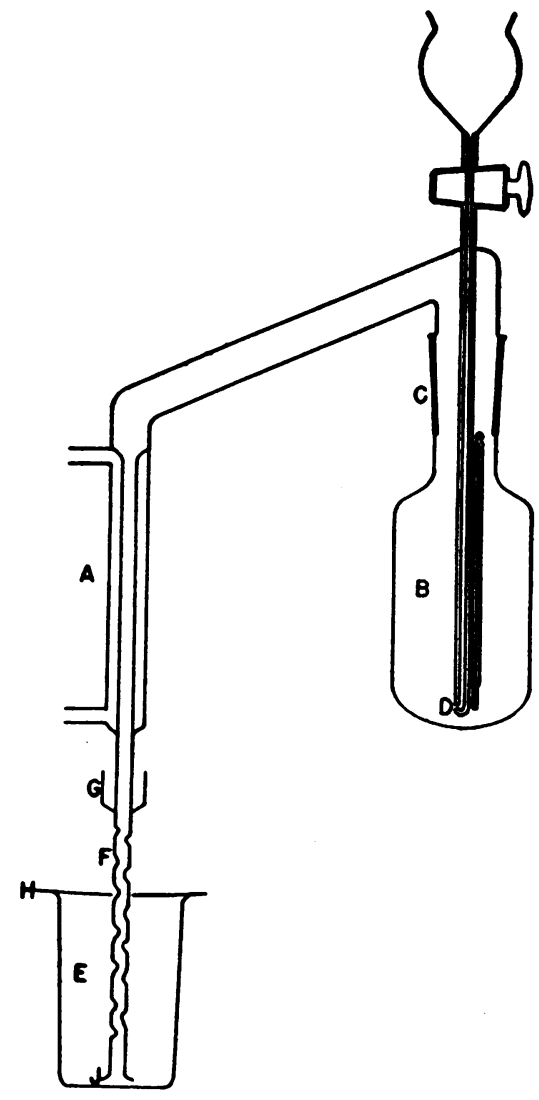

FIG. 2.

The digestion flasks are of diameter and height to be centrifuged in $250 \mathrm{ml}$. cups. They should be of uniform height so that the outlet of the dropping funnel of the condenser unit will be beneath the surface of the liquid and will not touch the bottom of the flask.

The Pyrex all-glass micro distilling head has a standard interchangeable $29 / 32$ ground glass joint (C). This rather large joint for micro apparatus and the short height above the digestion flask (B) have been used so that the iodine and steam may distill as quickly and freely as possible. For rapid boiling during distillation the flame from a Tyrrell burner plays directly on the flask without insulation. To prevent extreme temperature changes at the bottom of the flask when cold fluid is admitted through the dropping funnel, its tip has been sealed and the outlet (D) made in the side of the tube. This outlet below the surface of the liquid permits admission of fluid from the dropping funnel without loss of volatilized iodine. The water-cooled condenser (A) has a dew cup (G), a necessary addition. Loss from spattering of the distillate is minimized by baffles (F) in the condenser below the water cooling jacket, by the flared tip $(\mathrm{J})$ and by the perforated watch glass $(\mathrm{H})$ which is used to cover the high form collecting beaker (E). Made by Macalaster Bicknell, 181 Henry Street, New Haven, Conn. tals are washed 10 times (13). Maximum allowable impurity after recrystallization is 1 gamma of iodine per gram of potassium permanganate.

Potassium permanganate, $2 \mathrm{~N}$. A solution of $60 \mathrm{gm}$. of recrystallized potassium permanganate in $1,000 \mathrm{ml}$. of water is standardized by its titration against $50 \mathrm{ml}$. of heated $0.2 \mathrm{~N}$ sodium oxalate in $5 \mathrm{ml}$. of $27 \mathrm{~N}$ sulfuric acid.

Ceric sulfate, $\mathrm{Ce}\left(\mathrm{SO}_{4}\right)_{2}, 0.1 \mathrm{~N}$, prepared from hydrated ceric oxide, $\mathrm{CeO}_{2} \cdot 2 \mathrm{H}_{2} \mathrm{O}$ or from ceric hydroxide, $\mathrm{Ce}(\mathrm{OH})$ ، $(15,17,26)$ (G. Frederick Smith Chemical Co., Columbus, Ohio). To $11.7 \mathrm{gm}$. of hydrated ceric oxide or $24 \mathrm{gm}$. of ceric hydroxide are added $165 \mathrm{ml}$. of $27 N$ sulfuric acid, followed cautiously by $50 \mathrm{ml}$. of water. This is digested five minutes at the boiling point with the beaker covered, after which it is cooled slightly before the gradual addition of $400 \mathrm{ml}$. of water. After heating, with stirring if undissolved crystals remain, the clear solution is decanted. The final solution should be $5.0 \mathrm{~N}$ with respect to sulfuric acid when diluted to 1,000 ml. Its oxidation concentration should be standardized by titrating in the presence of iodide to a permanent yellow color with $0.1 \mathrm{~N}$ sodium oxalate or $0.1 \mathrm{~N}$ arsenious acid solution which need not be free from iodine.

Arsenious acid solutions, $0.3 N$ in $0.25 N$ sulfuric acid; and $0.3 N$ in $1.0 N$ sulfuric acid $(15,17,26)$. To $60 \mathrm{gm}$. of arsenic trioxide, $\mathrm{As}_{2} \mathrm{O}_{3}$ (Mallinckrodt Analytical reagent), in a $2,000 \mathrm{ml}$. Erlenmeyer flask are added 1,000 $\mathrm{ml}$. of water and $72 \mathrm{ml}$. of concentrated sulfuric acid. With glass beads to prevent bumping, the reagent is heated rapidly and boiled for 15 to 30 minutes until the crystals dissolve. After cooling in a refrigerator, the supernatant fluid is decanted and the crystals are washed with three separate portions of water. By titrating the supernatant liquid against $0.1 N$ ceric sulfate in the presence of iodide, the amount of arsenious acid which has recrystallized can be calculated. The recrystallized reagent is dissolved and diluted to make a $0.3 \mathrm{~N}$ arsenite solution. Two solutions are made, one in $1.0 \mathrm{~N}$ and one in $0.25 \mathrm{~N}$ sulfuric acid. After dilution $2 \mathrm{ml}$. of $0.3 N$ arsenious acid in the presence of iodide should require from 5.8 to $6.2 \mathrm{ml}$. of $0.1 \mathrm{~N}$ ceric sulfate to produce a permanent yellow color. Arsenite solutions seem to be more stable if stored in the dark with a small piece of metallic arsenic in each bottle. Metallic arsenic should not be used during preparation and boiling of the solutions because arsene may be formed.

Oxalic acid, $0.15 \mathrm{~N}$. The solution is prepared from oxalic acid (Mallinckrodt) recrystallized as described previously (13) except that $500 \mathrm{ml}$. of water are used.

Potassium iodide standards. Into each flask in which a potassium iodide solution is prepared $1 \mathrm{ml}$. of $0.3 \mathrm{~N}$ arsenious acid in $0.25 \mathrm{~N} \mathrm{H}_{2} \mathrm{SO}$, should be introduced in advance to keep the iodide in the reduced state and prevent adsorption of iodide on the walls of the vessels (26). $5.233 \mathrm{gm}$. of potassium iodide are dissolved and diluted to 1 liter to yield a primary standard solution containing $4 \mathrm{mg}$. of iodine per $\mathrm{ml}$. A secondary standard containing 40 gamma of iodine per $\mathrm{ml}$. is made by dilut- 
ing $10 \mathrm{ml}$. of the primary standard to a liter. By diluting $2.5 \mathrm{ml}$. of the secondary standard to a liter, a tertiary standard containing 0.10 gamma of iodine per $\mathrm{ml}$. is made, of which $1 \mathrm{ml}$. is equivalent to $1 \mathrm{ml}$. of blood serum containing 10 gamma per cent of iodine. Both primary and secondary standards deteriorate only slowly when refrigerated. A new tertiary standard should be prepared every third day.

\section{Procedure}

Precipitation. $1 \mathrm{ml}$. of blood serum is precipitated in the digestion flask, while shaking, with $8 \mathrm{ml}$. of zinc sulfate solution and $1 \mathrm{ml}$. of $0.75 \mathrm{~N}$ sodium hydroxide. After centrifuging for 20 minutes at 2,000 r.p.m. the supernatant liquid is decanted. Thereafter four times the precipitate is dispersed and washed with 20 to $30 \mathrm{ml}$. of water, centrifuged for 20 minutes, and the supernatant fluid discarded. The more dilute zinc sulfate and sodium hydroxide reagents recommended by Somogyi (25) for precipitation of serum yield cloudy filtrates which might contain protein. The amount of inorganic iodide in the supernatant wash can be measured by evaporating the complete washings to an appropriate volume and treating the remaining fluid as if it were a distillate.

Digestion. To the precipitate are added $12 \mathrm{ml}$. of $2 \mathrm{~N}$ potassium permanganate solution, followed after 15 to 20 minutes by $18 \mathrm{ml}$. of $27 \mathrm{~N}$ sulfuric acid added while shaking. This time should not be shortened because if it is, more permanganate will be required. Digestion by heating to $180^{\circ} \mathrm{C}$. is begun. 10 to 15 minutes, rather than immediately, after the addition of sulfuric acid so that the initial heating need not be as cautious. An ebullator and shaking prevent bumping; granules interfere with the tip of the distillation apparatus.

Distillation. The digestion flask and distillation condenser are connected. The tip of the condenser is placed in a $100 \mathrm{ml}$. high form Pyrex beaker under the surface of a solution of $0.5 \mathrm{ml}$. of arsenite solution in $0.25 \mathrm{~N}$ sulfuric acid and about $5 \mathrm{ml}$. of water. Six $\mathrm{ml}$. of acid arsenite solution $(1 \mathrm{ml}$. for each $3 \mathrm{ml}$. of sulfuric acid employed for digestion) are admitted from the dropping funnel into the digestion flask. Next, $0.15 N$ oxalic acid is added gradually while the flask is heated with a mild flame and the connected apparatus is shaken gently to dissolve any salts in the digest and prevent bumping. Just before the end-point, while the solution is boiling, between 120 and $130^{\circ} \mathrm{C}$, , oxalic acid is added by drops until decolorization is complete. To insure complete reduction after all traces of permanganate color have disappeared, an excess of $0.5 \mathrm{ml}$. of oxalic acid is added. A greater excess, a more concentrated solution or higher temperatures must be avoided, because oxalic acid in the distillate gives false high values in the final measurement of iodide. The heat is now increased so that the mixture boils violently to volatilize the iodine completely. Distillation is continued for at least 10 minutes while approximately $60 \mathrm{ml}$. of water are admitted through the dropping funnel in portions of about 3 to $4 \mathrm{ml}$. whenever the temperature approaches $133^{\circ} \mathrm{C}$. If the tem- perature rises above $135^{\circ} \mathrm{C}$. erroneous high values may be obtained. Spattering of the distillate may be diminished by lowering the beaker as the volume of distillate increases, but the tip of the condenser should be beneath the surface of the liquid until the last $4 \mathrm{ml}$. of water are added, when the collecting beaker is lowered so that all iodine will be washed out of the condenser.

Measurement of iodide in distillate. The distillate, after addition of a small ebullator, is concentrated on an electric plate at a heat which requires 30 to 40 minutes to reduce the volume to 3 to $4 \mathrm{ml}$. Further evaporation causes loss of iodide. The distillate is then transferred to a colorimeter tube calibrated at $5.5 \mathrm{ml}$. After addition of $0.5 \mathrm{ml}$. of arsenite solution in $1.0 \mathrm{~N}$ sulfuric acid, the mixture is diluted to the mark. Distillates from sera which are suspected to contain more than 12 gamma per cent of iodine are concentrated to only $9.5 \mathrm{ml} ., 0.5 \mathrm{ml}$. of arsenite in $0.25 \mathrm{~N}$ sulfuric acid is added, and half of the mixture with $0.5 \mathrm{ml}$. of arsenite in $1.0 \mathrm{~N}$ sulfuric acid is used for colorimetric recording.

The tube is placed in the temperature-controlled block of the Chaney recording colorimeter (15). After approximately five minutes, when the sample has reached the temperature of the block, some constant temperature between 30 and $35^{\circ} \mathrm{C}$., $0.5 \mathrm{ml}$. of $0.1 \mathrm{~N}$ ceric sulfate is added, the sample is well mixed with a stirring rod and transferred to the colorimeter position. A constant record is taken of the reduction of ceric sulfate for three to 10 minutes, long enough to yield a line 1 to 1.5 inches long. The angle made by the recording instrument is measured with a protractor. The corresponding cotangent is obtained from standard tables.

Calculations. Chaney (15) has shown that the cotangents of the angles recorded by his colorimeter bear a rectilinear relation to the concentrations of iodine. The slope and position of the curve defining this relation may, however, vary with the instrument, the reagents, and the temperature at which the color is developed. It is, therefore, necessary to construct a line with concentrations of iodine on one axis and cotangents from analyses of known solutions of iodide on the other. Since the cotangent is a cubic parabolic function of the angle, when the latter exceeds an optimum value, the error of reading increases rapidly. Although the line relating cotangents to iodine appears to be straight over a greater range and can be extended for practical purposes to 15 gamma per cent, the error is smallest in the range from 2 to 8 gamma per cent. For derivation of the line, standard solutions are submitted to the following procedures.

1. An appropriate quantity $(0.2$ to $1.2 \mathrm{ml}$.) of the tertiary potassium iodide standard is added to a zinc hydroxide precipitate which has been washed twice. The mixture of iodide and precipitate is then subjected to the digestion, distillation and colorimetric procedures prescribed for serum; however, the volume of potassium permanganate is reduced to $7 \mathrm{ml}$. to produce a digest which will require the same amount of oxalic acid and the same time for digestion as a sample of serum. If the permanganate and oxalic acid have been recrystallized 
properly, recoveries on distillates from only $7 \mathrm{ml}$. do not differ appreciably from recoveries on $12 \mathrm{ml}$. of $2 N$ potassium permanganate. Because such a large quantity of permanganate causes bumping or foaming during reduction of the digest, $12 \mathrm{ml}$. need be used only to test a fresh preparation of permanganate.

2. An appropriate quantity $(0.2$ to $1.2 \mathrm{ml}$.) of the tertiary potassium iodide standard is placed in a colorimeter tube. After addition of $0.5 \mathrm{ml}$. of arsenite in $0.25 \mathrm{~N}$ sulfuric acid and $0.5 \mathrm{ml}$. of arsenite in $1.0 \mathrm{~N}$ sulfuric acid, the solution is diluted to $5.5 \mathrm{ml}$. When the tube has been brought to the proper temperature, $0.5 \mathrm{ml}$. of ceric sulfate is added and the colorimetric measurement is made as described above.

If there is no iodine in the reagents and no possible loss in the course of digestion and distillation, the curves from procedures 1 and 2 should coincide; but there seems to be a slight, though systematic, difference between the two curves. Both give straight lines. The line does not pass through the origin because ceric sulfate with arsenite fades slightly, even in the absence of iodine. The line derived from the whole procedure, including distillation, has a little higher intercept and a slightly smaller slope than that from the simple colorimetric second procedure, suggesting that there may be minute quantities of contaminating iodine in the reagents and equally small losses of iodine in the procedure. The differences between the two lines are hardly outside the limits of statistical deviation and seem to be proportional to the amounts of iodine present. If, however, the reagents should be to any degree contaminated, these differences would be exaggerated. Consequently, although the standard curve for estimation of iodine should be derived from the first procedure, it is well to check by the second in order that gross contamination or losses may be detected. To determine whether the arsenite for collection of the distillate is adequate to hold iodine without loss by volatilization, 0.5 or $1.0 \mathrm{ml}$. of the tertiary potassium iodide standard may be added to $0.5 \mathrm{ml}$. of arsenite in $0.25 \mathrm{~N}$ sulfuric acid in a collecting beaker containing $60 \mathrm{ml}$. of water and the mixture carried through the evaporation and colorimetric procedures used for distillates. A curve constructed by the first procedure should be checked at frequent intervals, probably daily, by a single analysis of a known iodide solution.

Theoretically, it should be possible to measure iodine by the difference between a blank containing only water and one containing a known amount of iodide solution, both run through the whole procedure. Actually, a water blank treated in this manner yields a greater value than does a solution containing the equivalent of 1 to 2 gamma per cent of iodine. This is obviously not a true blank, but the result of some peculiar behavior of the reagents, presumably the arsenite, in the absence of iodine.

Accuracy. In 95 consecutive analyses of sera containing up to 12.0 gamma per cent of SPI, duplicate samples checked with a maximum difference of 1.3 , an average difference of 0.48 , and a standard deviation of \pm 0.55 gamma per cent. A solution of thyroxine estimated to contain 0.058 gamma of iodine was added, before precipitation of proteins, to serum which, by analysis, contained 0.059 gamma of iodine. Duplicate analyses gave values of 11.0 and 11.1 gamma per cent, the theoretical value being 11.7 gamma per cent. Duplicate analyses were made of serum precipitates of measured iodine content to which known amounts of potassium iodide had been added. The average recoveries were 95 to 100 per cent, with a maximum divergence of 0.4 gamma from the calculated value. Agreement with the macro technique of Riggs and Man $(13,14)$ is satisfactory.

\section{Remarks}

Although oxalic acid had proved satisfactory as a reducing agent in the Riggs and Man $(13,14)$ method for measurement of iodine in $6 \mathrm{ml}$. aliquots of serum, recoveries were low when oxalic acid alone was employed to reduce digests of only $1 \mathrm{ml}$. of serum. Since arsenious acid is required for the final measurement of iodide in the present procedure, the need for an additional reagent was eliminated by reducing the digest with a combination of arsenious and oxalic acids.

According to Chaney (15) the fading of the color of ceric sulfate reduced by arsenite in the presence of iodide is optimal when the concentration of sulfuric acid is between 0.5 and $1.2 \mathrm{~N}$; Riggs (27) recommends $1.0 \mathrm{~N}$. To achieve a final concentration above $0.5 N$ in the $6 \mathrm{ml}$. of solution used for color development, it was found expedient to add $0.5 \mathrm{ml}$. of arsenite in $1.0 \mathrm{~N}$ sulfuric acid and to use ceric sulfate in $5.0 \mathrm{~N}$ sulfuric acid.

The addition of chloride which Barker (22) has employed to increase the fading of color was abandoned because it did not appear to enhance the accuracy of the procedure. Chaney reports that chloride disturbs the rectilinear relation of iodide to ceric sulfate and can be the cause of serious error (15).

The continuously recording colorimeter requires of the technician less care for timing and temperature control and eliminates the use of selected and expensive tubes which would be required for the spectrophotometer. Since only the rate of fading is recorded, it is not necessary to use absolutely uniform tubes, though these should be of the same bore and thickness. In the absence of a continuously recording colorimeter, it should be possible theoretically to measure with a spectrophotometer the rate of fading of ceric sulfate and arsenite.

\section{RESULTS}

Seventy female and 10 male normal adult individuals had a maximal SPI value of 8.6 , a minimal of 3.8, gamma per cent, and a mean value of 5.4 gamma per cent (standard deviation \pm 0.94 ). Three normal females had values of 7.5, 7.8 and 8.6 gamma per cent. The woman with an iodine of 8.6 gamma per cent was a laboratory worker who, on another occasion, was found to have 6.0 gamma per cent of precipitable iodine in her serum. In- 
TABLE I

SPI on three consecutive days in normal individuals

\begin{tabular}{c|c|c|c|c}
\hline \multirow{2}{*}{ Subject } & \multicolumn{2}{|c|}{ Serum precipitable iodine } & Greatest \\
& Day 1 & Day 2 & Day 3 & \\
\cline { 2 - 5 } difference
\end{tabular}

asmuch as exclusion of either value from the normal series did not seem justifiable, both measurements are included. This is the only instance in which two values from the same individual are depicted. These three highest values exceed the mean by more than twice the standard deviation. If they are excluded, the maximum value becomes 7.1 gamma per cent and the mean 5.0 gamma per cent (standard deviation \pm 0.68 ). Though but 10 males were included, no obvious sex difference was apparent.

In order to test whether SPI in a given individual remains as constant over short intervals of time as it does over long (28), the SPI was determined in seven normal individuals on three consecutive days (Table I). In six of the seven subjects the variation of SPI was less than 1 gamma per cent.

The SPI in hyperthyroidism varied from 8.0 to 48.2 gamma per cent, with four exceptions. These four patients had hyperthyroidism as determined by the course of the disease and the response to therapeutic measures despite initial SPI values of 7.1, 7.4, 7.8 and 7.8 gamma per cent.

The SPI in hypothyroidism ranged from 0 to 3.0 gamma per cent. Three patients with characteristic hypothyroidism who were not receiving thyroid substance had SPI's as high as 2.9 gamma per cent. Two values of 2.9 and one of 3.5 gamma per cent were total iodines in which inorganic iodine in serum may have increased the values. The reductions of iodine in hypothyroidism following subtotal thyroidectomy were similar to those of patients with spontaneous thyroid hypofunction. The values obtained in those patients taking inadequate amounts of desiccated thyroid fall toward the upper part of the hypothyroid range.
In both the hyper- and hypothyroid groups only patients with characteristic signs and symptoms have been included. Such selection of data necessitates the omission of certain patients with questionable hyper- or hypothyroidism. Some of these patients had SPI values which approached the range of normal individuals. Such selection would not be justified except in this attempt to define the range of values in entirely characteristic clinical cases. To be a most useful diagnostic aid in recognition of true thyroid abnormalities, correct interpretation of values of SPI which differ but little from the normal range must be possible. Also, conditions other than thyroid disorders in which a value of SPI beyond the normal range is sometimes found must be recognized. Therefore, in a consecutive series of 1,895 patients involving 4,218 observations of SPI, an attempt was made to correlate the precise clinical conditions found with the SPI and to determine the significance of the latter.

Values below 3.8 gamma per cent were found in 120 patients who did not have authentic hypothyroidism (Table II). The diagnoses of 53 pa-

TABLE II

Patients with serum precipitable iodine values below 3.8 gamma per cent

\begin{tabular}{|c|c|c|c|}
\hline & \multirow{2}{*}{$\begin{array}{c}\text { Number } \\
\text { of } \\
\text { patients }\end{array}$} & \multicolumn{2}{|c|}{$\begin{array}{c}\text { Serum } \\
\text { precipitable } \\
\text { iodine }\end{array}$} \\
\hline & & $\begin{array}{l}\text { Mini- } \\
\text { mum }\end{array}$ & $\underset{\text { mum }}{\text { Maxi- }}$ \\
\hline & & $\underset{\%}{\operatorname{gamma}}$ & $\underset{\%}{\operatorname{gamma}}$ \\
\hline Hypothyroidism & 120 & 0.0 & 3.7 \\
\hline Thyroid Adenomata & 6 & 2.7 & 3.4 \\
\hline $\begin{array}{l}\text { After Discontinuing Thyroid } \\
\text { After Propylthiouracil }\end{array}$ & 4 & 2.0 & 3.7 \\
\hline $\begin{array}{l}\text { After Propylthiouracil } \\
\text { After Subtotal Thyroidectomy }\end{array}$ & $\begin{array}{l}2 \\
1\end{array}$ & $\begin{array}{l}3.0 \\
3.4\end{array}$ & 3.2 \\
\hline Pituitary Disease & 16 & 1.2 & 3.7 \\
\hline Abnormal Pregnancy & 4 & 2.7 & 3.7 \\
\hline Addison's Disease & 2 & 2.1 & 3.0 \\
\hline $\begin{array}{l}\text { Cirrhosis of the Liver } \\
\text { Infectious Hepatitis }\end{array}$ & 6 & 0.6 & 3.7 \\
\hline Nephrosis & $\begin{array}{l}1 \\
6\end{array}$ & $\begin{array}{l}3.4 \\
0.8\end{array}$ & 3.7 \\
\hline Intercapillary Glomerulosclerosis & 3 & 2.3 & 2.3 \\
\hline $\begin{array}{l}\text { Constrictive Pericarditis } \\
\text { Severe Rheumatic Heart Disease }\end{array}$ & 1 & $\begin{array}{l}3.0 \\
1.9\end{array}$ & \\
\hline Nephritis & 3 & 2.8 & 3.5 \\
\hline Xanthomatosis & 1 & 3.0 & \\
\hline Steatorrhea & 1 & 1.4 & \\
\hline $\begin{array}{l}\text { Infections } \\
\text { After Amputation }\end{array}$ & $\begin{array}{l}5 \\
1\end{array}$ & $\begin{array}{l}1.9 \\
3.5\end{array}$ & 3.7 \\
\hline After Mercuhydrin & 1 & 2.1 & \\
\hline $\begin{array}{l}\text { Hypertensive Cardiovascular } \\
\text { Disease }\end{array}$ & 2 & 2.9 & 3.7 \\
\hline Unclassified & 53 & 2.6 & 3.7 \\
\hline
\end{tabular}


tients could not be definitely established because the available clinical data were insufficient. However, among this group were 19 patients with psychiatric disorders whose symptoms were so diverse and diagnoses so different that any classification is impossible. Low SPI has been reported in patients shortly after discontinuing exogenous thyroid (29), and after subtotal thyroidectomy (12). Hypothyroidism may follow the administration of an antithyroid drug (30). The values obtained in patients with thyroid adenomata may indicate that degeneration has occurred and that the patients have hypothyroidism. The occurrence of a diminished SPI in pituitary disease (8), Addison's disease (9), abnormal pregnancy (10), and nephrosis $(7,11,31)$ has been previously reported. In addition, in this series the SPI has been found low in six patients with cirrhosis of the liver as well as in certain patients with intercapillary glomerulosclerosis, nephritis, steatorrhea, xanthomatosis, and constrictive pericarditis. All of these patients had metabolic disturbances sufficiently severe to cause electrolyte abnormalities, low serum proteins, or a change in the lipids. The changes in the serum proteins are not in themselves responsible for the low SPI as there is no linear correlation between the concentrations of these two substances. Also a low SPI does not always accompany a low serum protein concentration (11). That processes that are capable of causing profound metabolic changes can also influence the SPI is possible and is supported by recent work upon the effect of stress (32). The hypoiodinemia found in five instances of severe infection and one instance shortly after an amputation of a leg may represent the effect of an injury reaction. Low values occurring in these conditions offer diagnostic difficulties that may only be resolved by observing the effect of exogenous thyroid substance.

Excluding these conditions, however, there remain only two patients whose SPI was unexpectedly low. Both of these patients had compensated hypertensive cardiovascular disease without evidence of hypothyroidism. No explanation is apparent. An SPI lower than 3.8 gamma per cent did not occur in a normal individual. With certain limited exceptions, a value lower than this indicates the presence of hypothyroidism.

In this series there were 35 patients whose SPI fell between 7.1 and 7.8 gamma per cent without clinical evidence of hyperthyroidism. These findings, together with the values observed in the completely normal individuals, indicate that the upper euthyroid limit of the SPI is 7.8 gamma per cent. Values above this were encountered in only 20 patients other than those who were pregnant (10) or had authentic hyperthyroidism. Instances of spuriously high values occurring during the treatment of hyperthyroidism with thiourea have been reported (33). Ten results between 7.8 and 19.2 gamma per cent proved to be falsely high due to previous administration of priodax; one value of 18.4 gamma per cent was found four months after pantopaque had been used; and one value of 9.2 gamma per cent occurred eight days after diodrast was injected (34). In two patients with acute thyroiditis the initial values were high ( 8.2 and 19.6 gamma per cent) but during convalescence the SPI returned to the normal range. In two patients with severe hepatitis SPI was 8.7 and 8.8 gamma per cent.

Other than these instances, only four patients were encountered with an unexplained high value of the SPI. In one obese subject, SPI of 8.5 gamma per cent was noted immediately after a rapid weight loss of 19 pounds. The other patients had anxiety state, involutional melancholia, and non-thrombocytic purpura. Inasmuch as none of these latter determinations was subsequently repeated, no precise evaluation can be made. With only six exceptions, values of SPI above 7.8 gamma per cent indicate the presence of hyperthyroidism or pregnancy.

\section{CONCLUSIONS}

1. A method has been devised which permits the measurement of the serum precipitable iodine (SPI) in $1 \mathrm{ml}$. of serum.

2. In 79 of 80 normal adults SPI lay between 3.8 and 7.8 gamma per cent.

3. SPI in 200 untreated patients with characteristic clinical signs and symptoms of hyperthyroidism lay between 8.0 and 27.0 gamma per cent. There were four low values of 7.1, 7.4, 7.8 and 7.8, and two high values of 30.2 and 48.2 gamma per cent.

4. SPI in 93 patients with hypothyroidism was 3.0 gamma per cent or less.

5. Consecutive observations on 1,895 patients 
were reviewed. SPI falls below 3.8 gamma per cent in certain conditions other than hypothyroidism, but not in normal individuals. Rarely does the SPI rise above 7.8 gamma per cent except in hyperthyroidism or pregnancy.

\section{BIBLIOGRAPHY}

1. Winkler, A. W., Diseases of the Thyroid Gland, in: Diseases of Metabolism (G. C. Duncan, Editor), Chapter 17. W. B. Saunders Co., Philadelphia, 1947.

2. Bassett, A. M., Coons, A. H., and Salter, W. T., Protein-bound iodine in blood. V. Naturally occurring iodine fractions and their chemical behavior. Am. J. M. Sc., 1941, 202, 516.

3. Talbot, N. B., Butler, A. M., Saltzman, A. H., and Rodriguez, P. M., The colorimetric estimation of protein-bound serum iodine. J. Biol. Chem., 1944, 153, 479.

4. Lowenstein, B. E., Bruger, M., and Hinton, J. W., The protein-bound plasma iodine in patients with thyroid disease. J. Clin. Endocrinol., 1944, 4, 268.

5. Connor, A. C., Swenson, R. E., Park, C. W., Gangloff, E. C., Lieberman, R., and Curtis, G. M., The determination of the blood iodine; a useful method for the clinical laboratory. Surgery, 1949, 25, 510.

6. Salter, W. T., Bassett, A. M., and Sappington, T. S., Protein-bound iodine in blood. VI. Its relation to thyroid function in 100 clinical cases. Am. J. M. Sc., 1941, 202, 527.

7. Perry, W. F., and Cosgrove, J. B. R., Protein-bound plasma iodine as an aid in the diagnosis of thyroid disease. Canad. M. A. J., 1949, 60, 602.

8. Peters, J. P., German, W. J., and Man, E. B., Serum precipitable iodine in patients with tumors of or near the pituitary. J. Clin. Endocrinol., 1949, 9, 1292.

9. Kydd, D. M., Man, E. B., and Liebow, A. A., Addison's disease and its effect upon the thyroid gland. In preparation.

10. Heinemann, M., Johnson, C. E., and Man, E. B., Serum precipitable iodine concentrations during pregnancy. J. Clin. Invest., 1948, 27, 91.

11. Peters, J. P., and Man, E. B., The relation of albumin to precipitable iodine of serum. J. Clin. Invest., 1948, 27, 397.

12. Winkler, A. W., Riggs, D. S., Thompson, K. W., and Man, E. B., Serum iodine in hyperthyroidism, with particular reference to the effects of subtotal thyroidectomy. J. Clin. Invest., 1946, 25, 404.

13. Riggs, D. S., and Man, E. B., A permanganate acid ashing micromethod for iodine determinations; values in blood of normal subjects. J. Biol. Chem., 1940, 134, 193.

14. Man, E. B., Smirnow, A. E., Gildea, E. F., and Peters, J. P., Serum iodine fractions in hyperthyroidism. J. Clin. Invest., 1942, 21, 773.

15. Chaney, A. L., Instrumental improvements for de- termination of protein bound iodine in blood. Indust. \& Engin. Chem., Analyt. Ed., in press.

16. Sandell, E. B., and Kolthoff, I. M., Micro determination of iodine by a catalytic method. Microchimica Acta, 1937, 1, 9.

17. Chaney, A. L., Improvements in determination of iodine in blood. Indust. \& Engin. Chem., Analyt. Ed., 1940, 12, 179.

18. Petit, D. W., Starr, P., and Chaney, A. L., Clinical and laboratory reliability of protein-bound blood iodine determinations. Am. J. Med., 1949, 6, 391.

19. Sappington, T. S., Halperin, N., and Salter, W. T., Iodine in blood and thyroid; analytical procedure for use with small samples; pharmacological range of concentrations. J. Pharmacol. \& Exper. Therap., 1944, 81, 331.

20. Salter, W. T., and McKay, E. A., Iodine in blood and thyroid of man and small animals. Endocrinology, 1944, 35, 380.

21. Taurog, A., and Chaikoff, I. L., On the determination of plasma iodine. J. Biol. Chem., 1946, 163, 313.

22. Barker, S. B., Determination of protein-bound iodine. J. Biol. Chem., 1948, 173, 715.

23. Connor, A. C., Curtis, G. M., and Swenson, R. E., A simplified method for the determination of the protein-bound blood iodine and its clinical application. J. Clin. Endocrinol., 1949, 9, 1185.

24. Man, E. B., and Siegfried, D. A., Notes on the use of redistilled water and of amylose in the estimation of serum iodine. J. Biol. Chem., 1947, 168, 119.

25. Somogyi, M., A method for the preparation of blood filtrates for the determination of sugar. J. Biol. Chem., 1930, 86, 655.

26. Chaney, A. L., Personal communication.

27. Carr, E. A., Jr., Graham, D. E., Ober, S., and Riggs, D. S., The catalytic effect of the chromic ion in the Barker method for protein-bound iodine determination. Science, 1950, 111, 552.

28. Danowski, T. S., Hedenburg, S., and Greenman, J. H., The constancy of the serum precipitable or proteinbound iodine in healthy subjects. J. Clin. Endocrinol., 1949, 9, 768.

29. Riggs, D. S., Man, E. B., and Winkler, A. W., Serum iodine of euthyroid subjects treated with desiccated thyroid. J. Clin. Invest., 1945, 24, 722.

30. Astwood, E. B., Treatment of hyperthyroidism with thiourea and thiouracil. J. A. M. A., 1943, 122, 78.

31. Peters, J. P., and Man, E. B., The significance of serum cholesterol in thyroid disease. $J$. Clin. Invest., 1950, 29, 1.

32. Williams, R. H., Jaffe, H., and Kemp, C., Effect of severe stress upon thyroid function. Am. J. Physiol., 1949, 159, 291.

33. Peters, J. P., Man, E. B., Kydd, D. M., Engstrom, W. W., and Waters, L. L., Toxic effects of antithyroid drugs. Yale J. Biol. Med., 1949, 22, 139.

34. Man, E. B., and Peters, J. P., Artifactual values of serum precipitable iodine. J. Lab. \& Clin. Med., 1950, 35, 280. 